\title{
Crónica del acto institucional del 8 de marzo. Igualdad de las Mujeres de la Asociación Española de Derecho del Trabajo y Seguridad Social (AEDTSS)
}

\author{
Chronicle of the institutional act of 8 March. Women's \\ Equality of the Spanish Association of Labour Law and \\ Social Security (AEDTSS)
}

\author{
Concha SANZ \\ Universidad de Castilla-La Mancha \\ ORCID ID: 0000-0001-9783-9272
}

Recibido: 9/3/2021

Aceptado: $26 / 3 / 2021$

doi: https://doi.org/10.20318/femeris.2021.6150

El Día Internacional de las Mujeres se celebra en muchos países del mundo como parte de un siglo de lucha por la igualdad, la justicia, la paz y el desarrollo. Es una fecha ineludible en la agenda de las instituciones desde que Naciones Unidas celebró su primera conmemoración en 1975, coincidiendo con la celebración del Año Internacional de la Mujer y, sobre todo, a partir de 1977 con la aprobación de la resolución que proclama el 8 de marzo como Día Internacional de la Mujer.

El 8 de marzo, por tanto, es una fecha destacada en el calendario internacional para recordar que la desigualdad de género aún es una realidad en todo el mundo y que si bien han sido muchos los logros alcanzados quedan muchas injusticias por superar.

Por todo ello un año más, la Asociación Española de Derecho del Trabajo y de la Seguridad Social, en colaboración con el Consejo Económico y Social y la Universidad Rey Juan Carlos, el 4 de marzo y en modalidad online, como auténticos conocedores de las necesidades reales de la ciudadanía y conscientes de la potencialidad de la igualdad, quieren que este acto institucional del día Internacional de la mujer sirva para debatir las maneras de impulsar la "Igualdad de género, sistema de clasificación profesional y valoración de puestos de trabajo".

Dña. María Emilia Casas Baamonte, en su función de presidenta de la AEDTSS a las 9.30 h. procede a la presentación de la jornada agradeciendo el gran éxito obtenido en la esta cuarta convocatoria en que la Asociación junto al CES realizan este acto institucional (casi 400 personas inscritas). 
Nos recuerda al mismo tiempo, que el año pasado este acto de la Asociación fue el último presencial antes de la situación de pandemia que aún en la actualidad mantenemos y por ello la realización del mismo este año 2021 no queda más remedio que sea en la modalidad online.

Hace hincapié en que el 2021 es una gran oportunidad para no dar ningún paso atrás ya que "nos ha costado mucho avanzar para ahora retroceder". Por esta razón, luchar por la igualdad, la no discriminación, la participación y el empoderamiento de las mujeres "no es un tema secundario, sino el tema central" por lo que debe ser un objetivo prioritario en las agendas de todas las instituciones tal y como indiqué al principio.

Posteriormente, D. Pedro Fernández Alén, presidente del CES, nos informa que como órgano consultivo del gobierno manejan una batalla transversal como eje permanente ya que en el mercado laboral queda mucho pendiente por hacer.

Todo ello, porque la vida económica y en particular el mundo laboral es uno de los ámbitos fundamentales de la promoción de la igualdad de oportunidades, así la conciliación de la vida personal, familiar y laboral sigue siendo una problemática compleja y conflictiva porque la falta de corresponsabilidad contribuye a sostener la discriminación laboral y salarial de las mujeres y constituye una de sus principales barreras para su desarrollo profesional.

Continua explicando que la corresponsabilidad social significa aumentar la implicación de las personas en el reparto de las responsabilidades domésticas y familiares para extenderse a otros agentes sociales, siendo el principio de igualdad de oportunidad entre hombres y mujeres, esencial para construir una sociedad justa, social y económicamente desarrollada.

Hace especial hincapié en las desigualdades que afectan a las mujeres del entorno rural y especial preocupación del freno de los avances e indicadores entre los jovenes, por todo ello la necesaria implicación de la gente joven para proyectar un futuro en igualdad, reivindicando este día, trabajando con el legado de quienes nos han precedido en la lucha por la igualdad y mirando al futuro con decisión ya que falta mucho por avanzar hacia un nuevo pensamiento ciudadano impregnado de perspectiva de género.

Se da comienzo al primer panel que preside D. Jaime Cabeza Pereiro, vicepresidente de la AEDTSS adelantándonos que el tema de este panel es un auténtico "elemento productor de discriminación" y por esa misma razón, la transparencia salarial en las empresas es un tema que "va de la mano" con el salario, debido a su importancia en el ámbito laboral y su repercusión en materia de igualdad.

No ha querido dejar pasar la posibilidad de comentarnos como la invisibilidad de los trabajos de cuidados, la feminización de la pobreza, las violencias machistas o la falta de libertad en las identidades sexuales o expresiones de género "en esta época de transición difícil" hace ineludible esta cita anual y por ello manifiesta la necesidad de ese compromiso institucional del CES y la AEDTSS.

La primera ponencia de este panel "Criterios y sistemas de promoción profesional y ascensos y no discriminación por razón de género" tiene como ponente a Dña. Gemma Fabregat Monfort de la Universidad de Valencia, que nos explica como respecto al proceso 
de selección, el papel de la negociación colectiva, en complementariedad con el plan de igualdad, debería garantizar la objetividad en la selección de la persona trabajadora que se va a contratar. Objetividad que puede venir condicionada, entre otras fórmulas, por una imparcialidad en el proceso de selección mediante la inclusión de determinadas pruebas a efectos de limitar en lo posible la discrecionalidad empresarial.

Junto a ello, nos revela que debería buscarse también una extensión de esas mismas pautas de objetivación de cara a la valoración sobre la superación o no del proceso de selección de que se trate, blindadas a cualquier tipo de discriminación directa o indirecta, de modo que el criterio finalmente elegido, descanse sobre la prestación a realizar y no sobre su consideración social.

Esta prohibición de discriminación directa o indirecta en la formación y promoción profesional nos revela que se constata en los artículos 22.4 y 24.4. del Estatuto de los Trabajadores, por alusión, respectivamente, a la discriminación en relación con la clasificación profesional y la promoción.

Igualmente nos explica que las discriminaciones producidas en el ámbito de la promoción tienen una incidencia directa también en la segregación del trabajo en la empresa, de forma vertical, condicionando la elección de personal trabajador destinado, a ocupar los puestos de mayor cualificación dentro del escalafón de la empresa.

Por todo ello, entiende que deberíamos hablar de un sistema de ascensos objetivo y no discriminatorio, incluyendo, por ejemplo, en función también de la realidad de la empresa, un sistema de ascensos que incorpore nuevas variables además de la entrevista entre empresaria/o y personal trabajador; determinación de criterios selectivos no discriminatorios, ni directa ni indirectamente; o acciones positivas para asegurar la promoción profesional de las mujeres en la empresa.

Dña. Patricia Espejo Megías de la Universidad de Castilla-La Mancha como ponente de la Asociación Juvenil de la AEDTSS nos presenta el tema de los" Criterios y sistemas de clasificación profesional y no discriminación por razón de género".

La profesora Espejo analiza la brecha salarial de género existente en las empresas, poniendo de relieve la existencia de ésta a pesar de los avances experimentados en cuanto a la participación femenina en el mercado laboral español.

Analiza lo que prevé la legislación en cuanto a la igualdad salarial, es decir, la situación actual del mercado laboral, así como las causas de este trato desigual poniendo énfasis en el papel que las responsabilidades familiares y domésticas y el rol de la mujer tienen en la misma. tras el análisis de la situación actual y su variación en los últimos años, en plantear medidas por parte de las empresas para poder garantizar la igualdad salarial que realmente debería existir en las organizaciones empresariales; aunque, si bien es cierto, conseguir una igualdad efectiva de los derechos entre ambos géneros implica la necesidad de transformar de forma importante la sociedad.

Destaca que la brecha salarial de género hace referencia a que, en general, las mujeres perciben retribuciones inferiores a las recibidas por los hombres. Es necesario diferenciar dos conceptos dentro de la brecha salarial: por un lado, la diferencia salarial y, por otro lado, la discriminación salarial. 
Después de un amplio debate al respecto de las dos intervenciones y un mínimo descanso por esta causa, empieza el segundo panel, que preside D. Guillermo L. Barrios Baudor, catedrático de la URJC, que además ha sido el encargado de la organización del evento al formar parte también de la AEDTSS como Gerente. El profesor Barrios da paso a las dos nuevas participantes valorando el alto nivel de las mismas en los temas que nos ocupan.

En esta primera ponencia del segundo panel, Dña. Sonia Pedrosa Alquézar de la Universidad de Zaragoza nos instruye sobre "Trabajo de igual valor y transparencia retributiva". Y como no podía ser de otro modo, explica que el Real Decreto 902/2020, de 13 de octubre, de igualdad retributiva entre mujeres y hombres, cuya entrada en vigor se difiere al 14 de abril de 2021, desarrolla reglamentariamente el artículo 28 del Estatuto de los Trabajadores (modificado por el RDL 6/2019, de 1 de marzo) concretando sus presupuestos y determinando el contenido de las obligaciones en diferentes aspectos como el concepto de trabajo de igual valor, la obligación del registro retributivo, los sistemas de clasificación profesional contenidos en los convenios colectivos y su necesaria vinculación con el registro y la transparencia retributiva a través de una correcta valoración de los puestos de trabajo, así como el derecho de las personas trabajadoras a acceder al contenido del registro.

Además nos revela que el desarrollo reglamentario, también se extiende a lo establecido en los artículos 22.3 y 12.4.d) del ET que establecen, respectivamente, la obligación de que la clasificación profesional se realice conforme a criterios libres de discriminación, y la garantía de ausencia de discriminación, tanto directa como indirecta, entre mujeres y hombres en el caso de los contratos a tiempo parcial.

Este real decreto, desarrolla también, en cumplimiento a lo dispuesto en el artículo 46.6 de la Ley Orgánica 3/2007, de 22 de marzo, para la igualdad efectiva de mujeres y hombres (introducido por el repetido RDL 6/2019), el concepto y contenido de las auditorías salariales y complementa la regulación del Real Decreto 901/2020, de 13 de octubre, por el que se regulan los planes de igualdad y su registro y se modifica el Real Decreto 713/2010, de 28 de mayo, sobre registro y depósito de convenios y acuerdos colectivos de trabajo.

Nos señala además, que uno de los impactos fundamentales será la mayor transparencia como consecuencia de la obligación de presentar y comunicar a los agentes sociales y empleados los resultados de los diagnósticos de igualdad, auditorías salariales y los salarios por nivel de responsabilidad.

Y para finalizar las ponencias de este segundo panel, un tema sustancial sobre la "Valoración de puestos de trabajo" que nos presenta Dña. Begoña García Gil. Universidad Rey Juan Carlos.

Nos avanza que la valoración de puestos de trabajo es un proceso mediante el cual se establece el "valor" que un puesto de trabajo tiene respecto al conjunto de los puestos en la empresa, centrándose en el puesto en sí mismo, independientemente del titular que lo ocupe.

Este valor o posicionamiento viene determinado principalmente por el nivel de responsabilidad y desempeño de determinadas funciones inertes al puesto y fundamentalmente por su impacto en los resultados de la compañía, por su vinculación directa, o indirecta, en su correcto funcionamiento y su eficacia y/o rentabilidad. Al establecer este 
valor del puesto podemos realizar una agrupación de distintos puestos en base a criterios comunes y posteriormente una nivelación de estos.

La valoración de puestos de trabajo se constituye en una herramienta muy importante para visibilizar y afrontar el hecho de que aún mujeres y hombres no ganan lo mismo por la realización del mismo trabajo o de trabajos distintos, pero de igual valor. En este sentido, una valoración de puestos de trabajo neutra respalda una "evaluación objetiva del puesto, independientemente de la persona que lo ocupe".

La profesora García nos facilita además datos sobre el tema animándonos a visitar la página web "sermujerytrabajo.es" que, como parte de un proyecto de investigación, ofrece toda la información sobre ser mujer en el mercado laboral.

Antes de la clausura de este acto, con la intervención de D. Fernando Lousada, coopresidente de la Comisión de Igualdad de la AEDTSS, se procede a la entrega del IV premio "8 de marzo. Igualdad de las mujeres" a Dña. Mirentxu Marín de la UPNA que lleva por título "Discriminación salarial indirecta y los sistemas de valoración de los puestos de trabajo".

Dña. María Luisa Delgado Jalón. Decana de la Facultad de Ciencias Jurídicas y Sociales de la URJC, ya que este foro de debate se realiza en este ámbito universitario, nos deleita con una frase del médico y escritor D. Gregorio Marañón "No son dos sexos superiores o inferiores el uno al otro; son distintos" para junto con Dña. María Emilia Casas Baamonde. Presidenta de la AEDTSS realizar una "clausura optimista" de la Jornada que se da cuando se realiza un "trabajo bien hecho", expresando el compromiso de la Asociación de continuar trabajando en este esfuerzo colectivo y coordinado contando como desde hace cuatro años con el CES en este objetivo común.

Y no se me ocurre mejor forma de termina esta crónica de la jornada que insistir en que la igualdad de género no es una cuestión de un día, ni de un mes, debe ser un compromiso ineludible de toda la ciudadanía en su conjunto y de este modo, que el 8 de marzo consolide lo alcanzado para poder seguir andando caminos de igualdad entre todos y todas. 